\title{
Detection of Sulfonamide Resistance Genes via in situ PCR-FISH
}

\author{
ANNA GNIDA ${ }^{1 \star}$, KATARZYNA KUNDA ${ }^{1}$, ALEKSANDRA ZIEMBIŃSKA ${ }^{1}$, ANETA ŁUCZKIEWICZ ${ }^{2}$ \\ EWA FELIS $^{1}$ and JOANNA SURMACZ-GÓRSKA ${ }^{1}$ \\ ${ }^{1}$ Environmental Biotechnology Department, Faculty of Power and Environmental Engineering, \\ Silesian University of Technology, Gliwice, Poland \\ ${ }^{2}$ Department of Water and Wastewater Technology, Faculty of Civil and Environmental Engineering, \\ Gdańsk University of Technology, Gdańsk, Poland
}

Submitted 15 June 2013, revised 5 December 2013, accepted 12 May 2014

\begin{abstract}
Due to the rising use of antibiotics and as a consequence of their concentration in the environment an increasing number of antibiotic resistant bacteria is observed. The phenomenon has a hazardous impact on human and animal life. Sulfamethoxazole is one of the sulfonamides commonly detected in surface waters and soil. The aim of the study was to detect sulfamethoxazole resistance genes in activated sludge biocenosis by use of in situ PCR and/or hybridization. So far no FISH probes for the detection of SMX resistance genes have been described in the literature. We have tested common PCR primers used for SMX resistance genes detection as FISH probes as well as a combination of in situ PCR and FISH. Despite the presence of SMX resistance genes in activated sludge confirmed via traditional PCR, the detection of the genes via microscopic visualization failed.
\end{abstract}

Ke y word s: Sulfamethoxazole resistance gene, activated sludge, FISH, in situ PCR

\section{Introduction}

The spread of drug resistance poses a significant threat to health. Diseases caused by antibiotic-resistant bacteria are difficult to treat, last longer and pose the risk of death. In addition, they also contribute to increased costs of treatment, because often their eradication requires the use of alternative and more expensive drugs. WHO (2013) stresses that antimicrobial resistance (AMR) is a problem of a global concern and among several factors that accelerate the emergence and spread of AMR quotes weak or absent antimicrobial resistance surveillance and monitoring systems. Antimicrobial resistance transfer occurs the most often among environmental bacteria exposed to unmetabolised pharmaceuticals or their metabolites. Wastewater treatment plants are known to be a great AMR reservoir and resistance transfer place. It has been proved (Silva et al., 2007) that there are more antibiotic resistant bacteria in treated wastewater than in raw wastewater. There is a need to develop methods suitable for fast and inexpensive detection of resistance genes in environmental samples enabling to follow the resistance transfer and its favoring factors.
There is a lack of a simple method for the tracking of genes to assess conditions that induce and maintain drug resistance phenomena at the level of single cell or particular population, especially in environmental samples. The aim of the study was to detect the selected resistance genes in activated sludge in situ and to visualize them via microscopic observations to recognize which group of activated sludge bacteria carries more resistance genes. Two ways have been chosen to reach the aim: fluorescence in situ hybridization (FISH) using PCR primer-based oligonuclotides probes and hybrid techniques in situ PCR and FISH, as in situ methods enable analysis directly in the environmental matrix, without the necessity of nucleic acids or cell extraction. In situ PCR has been used for the visualization of specific genes (Hodson et al., 1995; Hoshino et al., 2003) while FISH is commonly used mainly for the detection and visualization of species or genera specific sequences in mixed environmental populations (Daims et al., 2005). Moreover, molecular methods such as PCR and FISH enable analysis without cell cultivation in contradiction to other techniques frequently used for drug resistance susceptibility assessment.

* Corresponding author: A. Gnida, Environmental Biotechnology Department, Faculty of Power and Environmental Engineering, Silesian University of Technology, 44-100 Gliwice, ul. Akademicka 2A, Poland; phone: 483223729 18; e-mail: anna.gnida@polsl.pl 
Sulfonamide resistance genes were chosen to verify the suitability of this hybrid method as the genes are frequently present in activated sludge. Sulfonamides (e.g. sulfamethoxazole, widely used throughout the world in medicine and veterinary in treatment and protection against infections) are known inhibitors of bacterial dihydropteroate synthase (DHPS). In bacteria, the enzyme DHPS participates in the folic acid pathway. Deficiency of folic acid prevents production of purines necessary for the synthesis of RNA (ribonucleic acid) and DNA (deoxyribonucleic acid), which leads to inhibition of bacterial cell growth (Brunton, 2007; Skold, 2001).

Bacterial resistance to sulfonamides occurs through mutations in the chromosomal DHPS gene $(f o l P)$ or through the acquisition of an alternative DHPS gene (sul), whose product has a low affinity for sulfonamides. Sul genes are the most common mechanism of sulfonamide resistance (Skold, 2000; Perreten and Boerlin, 2003). There are three sul genes encoding resistance to sulfonamides found Gram-negative bacteria plasmids: sul1, sul2 and sul3 (Grape et al., 2003; Antunes et al., 2005). The sul 1 gene is mostly found linked to other resistance genes in class 1 integrons. The sul 2 is usually located on small plasmids of the inc $\mathrm{Q}$ group, or on small plasmids represented by pBP1 (Antunes et al., 2005). The sul3 gene specifies a 263 -amino-acid protein similar to a dihydropteroate synthase encoded by the $54-\mathrm{kb}$ conjugative plasmid pVP440 from Escherichia coli (Perreten and Boerlin, 2003). Resistance to sulfonamides is generally attributed to the presence of sull and sul2 genes.

\section{Experimantal}

Materials and Methods

Activated sludge sampling. Samples of activated sludge were collected from municipal wastewater "Zabrze Śródmieście" located in Zabrze, Poland. Acti- vated sludge samples were taken from nitrification chamber and settling tank in the wintertime and summertime (4 samples). A sample of activated sludge was treated differently for various methods. That dedicated for PCR was frozen and stored at $-20^{\circ} \mathrm{C}$. That used for FISH was immediately fixed with $4 \%$ paraformaldehyde (incubation time of 90 minutes, $4^{\circ} \mathrm{C}$ ) and after washing step with $1 \times$ PBS stored at $-20^{\circ} \mathrm{C}$.

Detection of SMX resistance genes by PCR. Total genomic DNA was isolated from sludge samples with the Fast DNA spin kit for soil (MPBiomedicals). Presence of DNA was determined with agarose $(0.8 \%$ in 1xTBE) electrophoresis. Fragments of the sul1 and sul2 gene coding the sulfamethoxazole resistance were amplified by PCR. PCR reactions contained $5 \mu \mathrm{M}$ primers, $1 \mathrm{X}$ PCR buffer, $20 \mu \mathrm{M}$ dNTPs, $1 \mathrm{mM} \mathrm{MgCl}$, and 1,5 U of GoTAQ Flexi DNA polymerase (Promega Corp., Madison, WI, U.S.A.) and were run in a C1000 Touch (BIO-RAD). Primer sequences for sul1 and sul2 amplification are presented in Table I. PCR was carried out under the following cycling regime: $5 \mathrm{~min}$ at $96^{\circ} \mathrm{C}$; $1 \mathrm{~min}$ at $55^{\circ} \mathrm{C}, 3 \mathrm{~min}$ at $70^{\circ}, 23$ cycles each of $15 \mathrm{~s}$ at $96^{\circ} \mathrm{C}, 30 \mathrm{~s}$ at $55^{\circ} \mathrm{C}$ and $3 \mathrm{~min} 72^{\circ} \mathrm{C}$. Final extension was carried out for $5 \mathrm{~min}$ at $72^{\circ} \mathrm{C}$ (Grape et al., 2003). The quality of PCR products was determined visually on a $1 \times \mathrm{TBE}, 0.8 \%$ agarose gel.

Detection of SMX resistance genes by FISH. Activated sludge samples were fixed with $4 \%$ paraformaldehyde. The detection of SMX resistance genes was carried out using fluorescence in situ hybridization (FISH) with probes whose nucleotide sequence was based on the sequence of forward PCR primer used for detection of SMX resistance genes (Kadlec et al., 2005). The 5 '-end of the oligonucleotide was modified with a fluorescent dye - Cy3 in order to visualize the hybridization product. The probes were obtained from Biomers (Ulm, Germany). In situ hybridization was performed as described previously by Daims et al. (2005).

Since the optimal hybridization conditions (hybridization and wash buffer composition) for detection of

Table I

Oligonucleotide probes used in this study

\begin{tabular}{|l|c|l|l|}
\hline Probe name & Method & \multicolumn{1}{|c|}{ Sequence (5'-3') } & \multicolumn{1}{c|}{ Reference } \\
\hline EUB 338 I & FISH & GCT GCC TCC CGT AGG AGT & Amann et al., 1990 \\
\hline EUB 338 II & FISH & GCA GCC ACC CGT AGG TGT & Daims et al., 1999 \\
\hline EUB 338 III & FISH & GCT GCC ACC CGT AGG TGT & Daims et al., 1999 \\
\hline SUL1 & FISH & CTA GGC ATG ATC TAA CCC TCG GTC & Kadlec et al., 2005 \\
\hline SUL2 & FISH & ACA GTT TCT CCG ATG GAG GCC & Kadlec et al., 2005 \\
\hline sul1F & PCR & ATG GTG ACG GTG TTC GGC ATT CTG A & Grape et al., 2003 \\
\hline sul1R & PCR & CTA GGC ATG ATC TAA CCC TCG GTC T & Grape et al., 2003 \\
\hline sul2F & PCR & GAA TAA ATC GCT CAT CAT TTT CGG & Grape et al., 2003 \\
\hline sul2R & PCR & CGA ATT CTT GCG GTT TCT TTC AGC & Grape et al., 2003 \\
\hline
\end{tabular}


sulfamethoxazole resistance genes are not known, hybridization was carried out with a use of $10 \%, 20 \%$, $30 \%, 40 \%$ and $50 \%$ formamide (FA) concentration in the hybridization buffer and adequate concentration of $\mathrm{NaCl}$ in washing buffer. Detection of the bacteria was made using a fluorescence microscope Motic400T. Before microscope observations, samples were embedded in Citifluor (Citifluor Ltd, United Kingdom) to reduce fluorochrome fading. Pictures were taken using camera Moticam Pro-285Acolor and Motic Images Plus 2.0 software.

Detection of SMX resistance genes by in situ PCR and FISH. Cell wall permeabilization and in situ PCR were carried out as described previously (Cheng and Hodson, 2001) with minor modifications. The main modification was the use of fluorescently labeled dUTP (dUTP-Cy3) together with standard mixture of dNTP in PCR in order to visualize the PCR product. Prior to cell wall permeabilization activated sludge was treated $1: 1$ with te lysozyme solution $(2 \mathrm{mg} / \mathrm{ml})$ for $15 \mathrm{~min}$ at room temperature. Further permeabilization was carried out optionally (see Table II) by treatment with DNase-free RNase at a final concentration of $5 \mu \mathrm{g} / \mathrm{ml}$ for $15 \mathrm{~min}$ at room temperature. Then, the samples were dehydrated sequentially in 50, 80 and 98\% ethanol for 3 min each. At this stage the samples on the slides were ready for in situ PCR and FISH analysis.

Several series of tests were performed according to the results of a previously performed series and designed to verify the suitability of the method of in situ PCR-FISH for the identification of resistance genes in activated sludge bacteria. The experiment series are summarized in Table II.

In series A (a1-a2) in situ PCR methodology described by Cheng and Hodson (2001) was used to check the possibility of using two available DNA polymerases - Klenow fragment 3'-5' exo (Jena Bioscience) or GoTaq Flexi DNA polymerase (Jena Bioscience). Series B (b1-b3) sought to determine the effect of RNase on the FISH results (b1 and b2) and the impact of the PCR reaction (high temperature) on the feasibility of FISH (reaction b1 and b3). Series C (c1-c2) was performed to determine whether a fluorochrome originated from labeled dUTP can be separated from the labeled molecule during the PCR and bind nonspecifically to activated sludge. A series D (d1-d3) was designed to check the feasibility of traditional in situ PCR (without using the fluorescently-labeled dUTP) combined with FISH to detect functional genes in activated sludge bacteria.

In situ PCR was used for amplification of the sul1 and sul2 (Table III) gene in the bacterial cells. The PCR mixture contained PCR buffer $1 \mathrm{x}, 5 \mu \mathrm{M}$ of each primer set (sul1R/sul1F and sul2R/sul2F), $200 \mu \mathrm{M}$ of each of deoxynucleotide, and $20 \mu \mathrm{M}$ of dUTP-Cy3, and $1 \mathrm{U}$ of DNA Polymerase. PCR was performed with the using of following temperature profile: $5 \mathrm{~min}$ at $96^{\circ} \mathrm{C} ; 1 \mathrm{~min}$ at $55^{\circ} \mathrm{C}, 3 \mathrm{~min}$ at $70^{\circ}, 23 \mathrm{cycles}$ each of $15 \mathrm{~s}$ at $96^{\circ} \mathrm{C}, 30 \mathrm{~s}$ at $55^{\circ} \mathrm{C}$ and $3 \min 72^{\circ} \mathrm{C}$. Final extension was carried out for $5 \mathrm{~min}$ at $72^{\circ} \mathrm{C}$.

Table II

Characterization of experiment series performed to optimize in situ PCR-FISH

\begin{tabular}{|c|c|c|c|c|c|c|c|c|c|c|}
\hline Series name & \multicolumn{2}{|c|}{ A } & \multicolumn{3}{|c|}{ B } & \multicolumn{2}{|c|}{$\mathrm{C}$} & \multicolumn{3}{|c|}{$\mathrm{D}$} \\
\hline Series goal & \multicolumn{2}{|c|}{$\begin{array}{l}\text { Polymerase } \\
\text { suitability }\end{array}$} & \multicolumn{3}{|c|}{$\begin{array}{l}\text { Effect of high temperature } \\
\text { and RNa-se on FISH }\end{array}$} & \multicolumn{2}{|c|}{ dUTP binding } & \multicolumn{3}{|c|}{ Feasibility of in situ PCR-FISH } \\
\hline Reaction name & a1 & a2 & b1 & b2 & b3 & $\mathrm{cl}$ & c2 & $\mathrm{d} 1^{*}$ & $\mathrm{~d} 2{ }^{*}$ & $\mathrm{~d} 3^{*}$ \\
\hline \multicolumn{11}{|c|}{ Sample pretreatment } \\
\hline Fixation with PFA & + & + & + & + & + & + & + & + & + & + \\
\hline Lysozyme treatment & + & + & + & + & + & + & + & + & + & + \\
\hline $\mathrm{RNa}$-se treatment & + & + & - & + & - & - & - & - & - & - \\
\hline Ethanol dehydration & + & + & + & + & + & + & + & + & + & + \\
\hline \multicolumn{11}{|c|}{ in situ PCR } \\
\hline Polymerase & $\mathrm{K}$ & $\mathrm{T}$ & \multirow{5}{*}{$\begin{array}{c}\text { not } \\
\text { perfor- } \\
\text { med }\end{array}$} & & - & - & - & $\mathrm{K}$ & $\mathrm{K}$ & $\mathrm{T}$ \\
\hline Primers sul 1 & + & + & & & - & - & - & - & + & + \\
\hline dUTP-Сy3 & + & + & & & - & + & - & - & - & - \\
\hline dNTPmix & + & + & & & - & - & - & + & + & + \\
\hline Probe EUBmix & - & - & & & - & - & + & - & - & - \\
\hline \multicolumn{11}{|c|}{ FISH } \\
\hline Formamide, \% & 35 & 35 & 35 & 35 & 35 & \multirow{3}{*}{$\begin{array}{c}\text { not } \\
\text { per- } \\
\text { formed }\end{array}$} & & 35 & $0-50$ & $0-50$ \\
\hline Probe EUBmix & + & + & + & + & + & & & + & + & + \\
\hline Probe SUL1 & - & - & - & - & - & & & + & + & + \\
\hline
\end{tabular}

$\mathrm{K}$ - Klenow-fragment polymerase; T - TAQ polymerase; ${ }^{*}$ - agarose electrophoresis of PCR product were made 
After in situ PCR, the products were filtered (pore size $0.2 \mu \mathrm{m}$; Whatman) and then washed with $1 \times \mathrm{PBS}$ to remove remaining nucleotides and primers. FISH was performed on the filters as described in the previous section. In order to detect all bacteria a mixture of three probes: EUB338 I, EUB338 II and EUB338 III were used at the ratio 1:1:1 (Daims et al., 1999). For series A, B, C and reaction d 1 the formamide concentration in the hybridization buffer was $35 \%$, while the reactions $\mathrm{d} 2$ and $\mathrm{d} 3$ were performed with a FA concentration of $0,10,20,30,40$ and $50 \%$. For microscopic observation each filter was placed on microscopic slide.

Quality of PCR products from reaction $\mathrm{d} 2$ and $\mathrm{d} 3$ was determined visually on a 1 xTBE $0.8 \%$ agarose gel.

\section{Results and Discussion}

Presence of SMX resistance genes in activated sludge. Activated sludge taken for analysis in the study were sampled from two different seasons as we had doubts if the SMX resistance bacteria are present all over the year in a quantity suitable for detection of their genes. It is known that antimicrobial agents (as sulfonamides) present in the environment induce the resistance transfer among bacteria (Suzuki and Hoa, 2012) resulting in their better survival in harsh conditions. The concentration of sulfonamides in wastewater changes between the seasons resulting from higher use in seasons when the incidence of infection is greater and consumption of sulfonamides higher, thus in the winter (Bhandari et al., 2008).

For detection of the genes in activated sludge bacteria, a DNA extraction and PCR were made using primers flanking the genes of interest. Agarose electrophoresis of the PCR products confirmed the presence of resistance genes sull, and sul2 in samples taken from both the nitrification chamber and sedimentation tank, regardless of the season (Fig. 1). These genes enable bacteria to be insensitive to the antibiotic due to the production of the modified enzyme (encoded by these genes) dihydropteroate synthase (DHPS).

Previously reported data indicated presence of sulfonamide resistance genes among environmental bacteria in different aquatic compartments. Sulfamethoxazole resistance genes (sul1, sul2 and sul3) were detected in shrimp ponds, a city canal and wastewater-feed fish ponds (Hoa et al., 2008). Sul1 and sul2 were the most abundant SMX resistance genes. The predominance of sul1 above sul2 in wastewater and lake was mentioned earlier Czekalski et al. (2012). Genes sulI and sulII were identified in bacteria isolated from faeces in dairy farms (Srinivasan et al., 2005), as well as in water and sediments from aquaculture (Pei et al., 2006) and in the rivers (Mohapatrafv et al., 2008) Gene sulI was

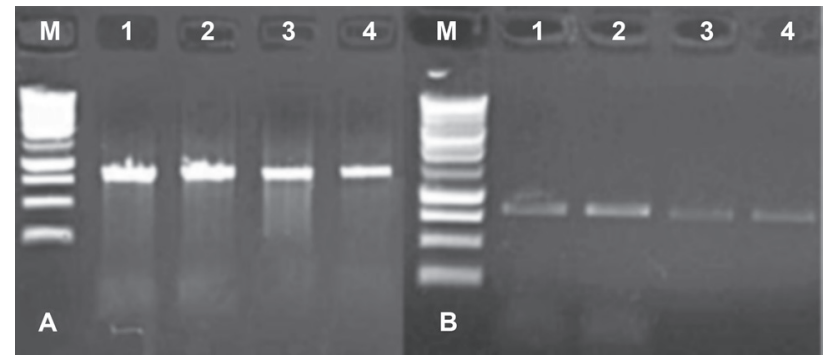

Fig. 1. Electrophoresis of PCR products

Figure A - summer samples, Figure B - winter samples; M - mass marker (100-1000 bp); position 1 and 3 - samples taken from nitrification tank, 2 and 4 - samples taken from settling tank; 1, 2 - primer set for sul1 (364 bp), 3 and 4 - primer set for sul2 (364 bp)

also detected in sewage treatment plants, river water and seawater (Zhang et al., 2009). Three genes carrying sulfamethoxazole resistance were also identified in sewage treatment plants in Germany (Szczepanowski et al., 2009) and Poland (Łuczkiewicz et al., 2013).

Detection of SMX resistance genes by FISH. Since no FISH probe had been designed and optimized, PCR primers were used as FISH probes to identify genes encoding sulfamethoxazole resistance (Table I). In order to estimate the conditions most suitable for hybridization, several hybridization conditions were tested, each time with different formamide concentration. Despite the presence of sulfamethoxazole resistance genes in activated sludge, no fluorescence signal originating from $\mathrm{Cy} 3$ was observed in all samples. Thus, we concluded that the detection of genes by FISH technique with the use of probes SUL1 and SUL2 had failed. The major limiting factor of the experiment was probably connected with small copy number of sulfamethoxazole resistance genes, resulting in signal intensity under the microscope detection level. While targeting $16 \mathrm{~S}$ rRNA by FISH the detection limit is $10^{3}-10^{4}$ cells. As the amount of resistance genes is much lower than that of rRNA the limit of their detection would be much higher. Techniques that intensify fluorescence signal, or increase the number of gene copies should be used to improve the results.

Detection of SMX resistance genes by in situ PCR and FISH technique. In order to amplify DNA, the fragment encoding sulfamethoxazole resistance, PCR was used together with both the non-labeled dNTPs and deoxyuridine triphosphate (dUTP) labeled with Cy3. dUTP-Cy3 was used for further visualization of the amplicons. To perform the PCR reaction the Klenow fragment of DNA polymerase I that is recommended for the synthesis of DNA with fluorescent nucleotide analogs was used. Besides Klenow fragment DNA polymerase, Taq polymerase was tested as well.

Since the detection of sulfamethoxazole resistance genes by traditional FISH failed, in situ PCR coupled with FISH was tested to reach the aim of this study. It 
Table III

Detection of fluorescence signal after in situ PCR-FISH

\begin{tabular}{|l|c|c|c|c|c|c|c|c|c|c|}
\hline \multicolumn{1}{|c|}{ Series name $^{*}$} & \multicolumn{2}{|c|}{ A } & \multicolumn{3}{c|}{ B } & \multicolumn{3}{c|}{ C } & \multicolumn{2}{c|}{ D } \\
\hline Reaction name $^{\star}$ & a1 & a2 & b1 & b2 & b3 & c1 & c2 & d1 & d2 & d3 \\
\hline Cy3 (red) & + & + & & & & + & & - & - & - \\
\hline 6-FAM (green) & - & - & + & - & $+/-$ & & - & - & - & - \\
\hline Cy3/FLUOS & - & - & & & & & & - & - & - \\
\hline
\end{tabular}

see Table II for explanation of characteristics of series and reactions

was assumed that during the in situ PCR sulfamethoxazole resistance genes are amplified to an efficient level for microscopic observation. Subsequent FISH was performed on the post in situ PCR mixture. In this case universal bacterial probes were used to detect the sulfamethoxazole resistance genes inside the activated sludge bacteria.

Several attempts were made to optimize the in situ PCR-FISH conditions. The series characteristics are given in Table II, while the results are presented in Table III. The attempts were performed on all four samples treated as a repetitions. All results were the same for all the samples. Red signals were observed as a result of in situ PCR-FISH, suggesting a positive response from fluorochrome $\mathrm{Cy} 3$ used during in situ PCR (dUTP-Cy3) or from probe SUL1 used in FISH, while the green signal originated from 6-FAM that was used to label probe EUBmix. Observation of both green and red fluorescence signal (Cy3/FLUOS) at a particular position of a microscopic field (an overlay of fluorescence signals) was regarded as an amplicon found inside a bacterial cell.

After the first series (reaction a1 and a2), it was not clear if the Klenow fragment of DNA polymerase, or Taq polymerase is suitable for further study. During the microscopic analysis it was found that hybridization of post in situ PCR mixture with EUBmix had failed. There were only signals characteristic for fluorochrome Cy3, that labeled dUTP used to visualize amplicons formed during in situ PCR. The absence of green signal does not allow to confirm that the observed red signal comes from the amplified fragment sull.

The series B aimed at finding the reasons for the lack of hybridization. Reactions were performed omitting in situ PCR step (reaction b1 and b2). As a result, it was found that the hybridization of activated sludge bacteria with the probe EUBmix occurred only when the samples were treated with lysozyme (reaction b1), which led to permeabilization of the cell wall so that it became permeable to the probe. There was no hybridization of activated sludge bacteria with the probe EUBmix if lysozyme and RNase were used together (reaction b2). The second series confirmed the suggestion that the use of RNase destroys the goal of hybridization - the genetic material (rRNA), and prevents proper identification of genes and microorganisms of interest. These series confirmed the suspicion that the use of RNase destroys the genetic material (rRNA), a goal during hybridization, and prevents the carrying out of this stage, and thus the identification of the microorganisms of interest. Thus, the protocol presented by Cheng and Hodson (2001) that was used in the study should be verified to be used for in situ PCR-FISH detection of genes in bacteria.

Subsequently, high temperature, which influences the activated sludge during in situ PCR, has an impact on the genetic material of activated sludge as well, and makes the hybridization difficult or impossible to carry out. The intensities of fluorescent signals observed after the hybridization were weak and close to the intensity of autofluorescence (background), while the activated sludge subjected to hybridization with probe EUBmix (allowing detection of all bacteria) without heating step resulted in a high intensity fluorescent signals derived from bacteria. Possibly the extra time or a change of formamide concentration in hybridization buffer would result in probe hybridization with genetic material of the activated sludge.

A third series (C), was designed to assess the possibility of the release of fluorochrome molecules during PCR (Table II). The reaction $\mathrm{cl}$ covered the performance of thermal profile as used in PCR ("PCR" performed without a use of reaction mixture, polymerase and primers). It revealed the presence of strong red signals. The signal was probably a result of high temperatures used during PCR that caused a formation of fragile bonds between fluorochrome and dUTP. As a consequence, the release of the fluorochrome from dUTP and its binding to many cells or intracellular components had occurred (Cheng and Hodson, 2001). The red fluorescence signal that was observed originated from $\mathrm{Cy} 3$, and was not specific for the sulfamethoxazole resistance genes, although the genes could be amplified during in situ PCR. In comparison to reaction $\mathrm{c} 1$, in the reaction $\mathrm{c} 2$ probe EUBmix instead of dUTP was subjected to temperature profile to check the possibility of de-labeling of FLUOS from EUB probe. Microscopic observations of product of reaction c2 showed an absence of signals from green fluorochrome which labeled the EUBmix probe used in the reaction. The mechanism of binding between nucleotide and $\mathrm{Cy} 3$ is other than that for dUTP-Cy3, and the bond was more stable at higher temperature.

The fourth series (D), encompassed PCR reactions without the use of dUTP and followed by FISH. The FISH was performed with two probes - SUL1 and EUBmix to detect sequence of reverse primer used in in situ PCR and all bacteria, respectively. As a result no signals from the fluorochrome FLUOS (derived from EUBmix) and Cy3 (derived from SUL1) were observed 
during microscopic analysis. This indicated the absence of hybridization. In this series, the PCR products were verified by agarose gel electrophoresis. The product was found in the case of reaction $\mathrm{d} 2$ and $\mathrm{d} 3$. In the reactions, different polymerases were used. Reaction d1 (lack of dUTP and primers in the reaction mixture) served as the negative control. The presence of this product indicates that during the PCR reaction gene sull was amplified. This reaction was performed several times, each time with another formamide concentration in hybridization buffer $(0-50 \%)$, to apply optimal hybridization conditions. Unfortunately, none of the tested reactions gave a positive result.

Summarizing the above, we failed to identify sulfamethoxazole resistance genes in nitrifying bacteria by the coupled in situ PCR - in situ hybridization techniques. However, this does not mean that this technique is useless in the identification of resistance genes but additional optimization is needed. We propose to treat the sludge only with lysozyme during the pretreatment step, extend the hybridization time, apply different concentrations of formamide in the hybridization buffer.

Other methods that could be used for the identification and visualization of resistance genes could be used as well. In order to perform detection based on FISH and primers flanking the investigated resistance gene as oligonucleotide probes the fluorescent signal must be significantly strengthened to detect a small number of copies. For this purpose the DOPE-FISH or CARD-FISH were designed. DOPE-FISH (Double Labeling of Oligonucleotide Probes for Fluorescence In Situ hybridization) is a FISH performed with the use of double labeled probes - at the 5 'and 3' end of tested fragment (Stoecker et al., 2010). CARD-FISH (catalyzed reporter deposition-fluorescence in situ hybridization) represents a method in which signal amplification is caused by use of an enzyme (Bobrow et al., 1989). The FISH probe is labeled with horseradish peroxidase (HRP). After the hybridization the sample is incubated with fluorescently labeled thyramid. The activity of HRP results in production of radical form of thyramid and its accumulation in a cell, close to hybrid with probe thus amplifying the fluorescence signal. However, application of this method requires careful and controlled permeabilization step to avoid disturbance of the cell structure by diffusion of large size probe. Intensification of the fluorescent signal during the application of in situ hybridization can be achieved using the so-called RING-FISH (Recognition of Individual Genes in a Single Bacterial Cell by Fluorescence In Situ hybridization) - the variety of traditional FISH method used to identify individual genes. The modification involves the use of polynucleotide probes labeled every 10-20 nucleotides and their use in high concentrations (approximately $250 \mathrm{ng} / \mathrm{ml}$ ), addition of denaturation step before hybridization and extension of hybridization time beyond $24 \mathrm{~h}$. The fluorescence signal obtained is visible as a distinctive ring. It is recommended to apply several times the labeled probe designed for DNA microarray as probes for the identification of resistance genes (Majtan et al., 2007). RING-FISH was successfully applied to the detection of beta-lactam resistance genes on plasmids (Zwirglmaier et al., 2004). This method is not often used, probably because of the considerable cost of polynucleotide probes, which lies in the difficulty of chemical labeling of the probe at least every 10 nucleotides. The authors of the publication ordered such a polynucleotide probe in two biotech companies. We wanted two polynucleotide fragments (with a length of 50 and 60 nucleotides) to be synthesized. There were oligonucleotides sull and sul2 used for microarray (van Hoek and Aarts, 2008). After several attempts of synthesis the companies cancelled the order completion excusing themselves by the impossibility of labeling the fragment 5-6 times. They were able to provide fragments of interest labeled maximum 3-times. A kind of compromise could be the generation of own polynucleotide probes labeled fluorescently through molecular genetics. Biotech companies recommend amplification and labeling of DNA during PCR. The purchase of a matrix in the form of a polynucleotide fragment of the desired DNA sequence, followed by its amplification in the presence of labeled nucleotides is then necessary. This method does not give any assurance that the labeled nucleotides are further apart than every 10 nucleotides, which is relatively important because the shorter distance between the fluorochromes causes quenching of fluorescent signal.

Conclusions. Sulfamethoxazole resistance genes were detected in activated sludge bacteria by PCR. Their visualization by FISH failed probably due to a low number of gene copies. To enrich their number and visualize them by microscopic techniques inside the bacterial cells a hybrid of in situ PCR and FISH was used. Performance of in situ PCR under activated sludge bacteria with the use of fluorescently labeled nucleotides was designed to amplify the resistance genes and simultaneously label them with a fluorescent dye.

In situ PCR and subsequent FISH were used to multiply certain resistance genes and detect and visualize them in bacterial cells by microscopic observations. The idea that FISH may be performed on post-in situ PCR mixture has been verified by detection of resistance genes in activated sludge bacteria. Detection of sulfamethoxazole resistance genes via in situ PCR and fluorescence in situ hybridization was not possible. After several attempts first we could not accomplishj labeling of amplicons during PCR and secondly hybridization following PCR. 


\section{Acknowledgments}

The research was financed by the Polish Ministry of Science and Higher Education under the project entitled "Transfer of antibiotics resistance in activated sludge bacteria" (project no N N 523493134).

\section{Literature}

Amann R.I., B.J. Binder, R.J. Olson, S.W. Chisholm, R. Devereux and D.A. Stahl. 1990. Combination of 16S rRNA-targeted oligonucleotide probes with flow cytometry for analyzing mixed microbial populations. Appl. Envir. Microbiol. 56: 1919-1925.

Antunes P., J. Machado, J.C. Sousa and L. Peixe. 2005. Dissemination of sulfonamide resistance genes (sul1, sul2, and sul3) in portuguese Salmonella enterica strains and relation with integrons. Antimicrob. Agents and Chemother. 49(2): 836-839.

Bhandari A., L. Close, W. Kim, R.P. Hunter, D.E. Koch and R. Surampalli. 2008. Occurrence of ciprofloxacin, sulfamethoxazole, and azithromycin in municipal wastewater treatment plants. Practice periodical of hazardous, toxic, and radioactive waste management 275

Bobrow M.N., T.D. Harris, K.J. Shaughnessy and G.J. Litt. 1989. Catalyzed reporter deposition, a novel method of signal amplification: application to immunoassays. J. Immunol. Methods 125: 279-285.

Brunton L., B. Chabner and B. Knollman. 2006. Goodman and Gilman's The Pharmacological Basis of Therapeutics. McGraw-Hill Professional, New York

Cheng F. and R.E. Hodson. 2001. In situ PCR/RT-PCR coupled with in situ hybridization for detection of functional gene and gene expression in prokaryotic cells, pp. 409-424. In: Paul H.J. (ed): Methods in Microbiology 30. Academic Press, San Diego, USA.

Czekalski N., T. Berthold, S. Caucci, A. Egli and H. Bürgmann. 2012. Increased levels of multiresistant bacteria and resistance genes after wastewater treatment and their dissemination into Lake Geneva, Switzerland. Frontiers in Microbiology 3(106): 2-18.

Daims H., A. Brühl A., Amann R., Schleifer K.-H. and M. Wagner. 1999. The domain-specific probe EUB338 is insufficient for the detection of all Bacteria: Development and evaluation of a more comprehensive probe set. Syst. Appl. Microbiol. 22: 434-444. Daims H., K. Stoecker and M. Wagner. 2005. Fluorescence in situ hybridization for the detection of prokaryotes, pp. 213-239. In: Molecular Microbial Ecology, ed. A.M. Osborn and J. Smith, Advanced methods in molecular microbial ecology. Bios-Garland, Abingdon, United Kingdom.

da Silva M.F., I. Vaz-Moreira, M. Gonzalez-Pajuelo, O.C. Nunes and C.M. Manaia. 2007. Antimicrobial resistance patterns in Enterobacteriaceae isolated from an urban wastewater treatment plant. Microbiol. Ecol. 60: 166-176.

Grape M., L. Sundstrom and G. Kronvall. 2003. Sulphonamide resistance gene sul3 found in Escherichia coli isolates from human sources. J. Antimicrob. Chemother. 52: 1022-1024.

Hoa P.T.P., L. Nonaka, P.H. Viet and S. Suzuki. 2008. Detection of the sul1, sul2, and sul3 genes in sulfonamide-resistant bacteria from wastewater and shrimp ponds of north Vietnam. Sci. Total Environ. 405: 377-384.
Hodson R., W. Dustman, R.P. Garg and M.A. Moran. 1995. In situ PCR for visualization of microscale distribution of specific genes and gene products in prokaryotic communities. Appl. Environ. Microbiol. 61(11): 4074-4082.

Hoshino T., S. Tsuneda, A. Hirata and Y. Inamori. 2003. In situ PCR for visualizing distribution of a functional gene "amoA" in a biofilm regardless of activity. J. Biotechnol. 105(1-2): 33-40.

van Hoek A. and H. Aarts. 2008. Microarray-based detection of antibiotic resistance genes in Salmonella. Food Anal. Methods. 1(2): 95-108.

Kadlec K., C. Kehrenberg and S. Schwarz. 2005. Molecular basis of resistance to trimethoprim, chloramphenicol and sulphonamides in Bordetella bronchiseptica. J. Antimicrob. Chemother. 56: 485-490.

Łuczkiewicz A., E. Felis, Z. Ziembińska, A. Gnida, E. Kotlarska, K. Olańczuk-Neyman and J. Surmacz-Górska. 2013. Resistance of Escherichia coli and Enterococcus spp. to selected antimicrobial agents present in municipal wastewater. J. Wat. Health, doi:10.2166/ wh. 2013.130

Majtan T., L. Majtanova, J. Timko and V. Majtan. 2007. Oligonucleotide microarray for molecular characterization and genotyping of Salmonella spp. strains. J. Antimicrob. Chemother. 60: 937-946.

Mohapatra H., S.S. Mohapatra, C.K. Mantri, R.R. Colwell and D.V. Singh. 2008. Vibrio cholerae non-O1, non-O139 strains isolated before 1992 from Varanasi, India are multiple drug resistant, contain intSXT, dfr18 and aadA5 genes. Environ. Microbiol. 10: 866-873.

Pei R., S.C. Kim, K.H. Carlson and A. Pruden. 2006. Effect of river landscape on the sediment concentrations of antibiotics and corresponding antibiotic resistance genes (ARG). Wat. Res. 40(12): 2427-2435.

Perreten V. and P. Boerlin. 2003. A new sulfonamide resistance gene (sul3) in Escherichia coli is widespread in the pig population of Switzerland. Antimicrob. Agents Chemother. 47(3): 1169-1172.

Skold O. 2000. Sulfonamide resistance Sulfonamide resistance: mechanisms and trends. Drug Resist. Updat. 3: 155-160.

Srinivasan V., H.M. Nam, L.T. Nguyen, B. Tamilselvam, S.E. Murinda and S.P. Oliver. 2005. Prevalence of antimicrobial resistance genes in Listeria monocytogenes isolated from dairy farms. Foodborne Pathog. Dis. 2: 201-221.

Stoecker K., C. Dorninger, H. Daims and M. Wagner. 2010. Double labeling of oligonucleotide probes for fluorescence in situ hybridization (DOPE-FISH) improves signal intensity and increases rRNA accessibility. Appl. Environ. Microbiol. 76(3), 922-926.

Szczepanowski R., B. Linke, I. Krahn, K.-H. Gartemann, T. Gützkow, W. Eichler, A. Pühler and A. Schlüter. 2009. Detection of 140 clinically relevant antibiotic-resistance genes in the plasmid metagenome of wastewater plant bacteria showing reduced susceptibility to selected antibiotics. Microbiol. 155: 2306-2319.

Suzuki S. and P.T.P. Hoa. 2012. Distribution of quinolones, sulfonamides, tetracyclines in aquatic environment and antibiotic resistance in Indochina. Front Microbiol. 3: 67.

WHO. 2013. Antimicrobial resistance. Fact sheet $\mathrm{N}^{\circ} 194$.

Zhang X-X., T. Zhang and H. Fang. 2009. Antibiotic resistance genes in water environment. Appl. Microbiol. Biotechnol. 82: 397-414. Zwirglmaier K., W. Ludwig and K.H. Schleifer. 2004.Recognition of individual genes in a single bacterial cell by fluorescence in situ hybridization - RING-FISH. Mol. Microbiol. 51(1): 89-96. 
